\title{
An unconditional prenatal income supplement is associated with improved birth and early childhood outcomes among First Nations children in Manitoba, Canada: a population-based cohort study
}

Jennifer E. Enns' ${ }^{1}$, Nathan C. Nickel', Mariette Chartier ${ }^{1}$, Dan Chateau', Rhonda Campbell², Wanda Phillips-Beck², Joykrishna Sarkar', Elaine Burland ${ }^{1}$, Alan Katz ${ }^{1,3}$, Rob Santos $^{1}$ and Marni Brownell ${ }^{\text {** }}$

\begin{abstract}
Background: In Manitoba, Canada, low-income pregnant women are eligible for the Healthy Baby Prenatal Benefit, an unconditional income supplement of up to CAD $\$ 81 /$ month, during their latter two trimesters. Our objective was to determine the impact of the Healthy Baby Prenatal Benefit on birth and early childhood outcomes among Manitoba First Nations women and their children.

Methods: We used administrative data to identify low-income First Nations women who gave birth 2003-2011 $(n=8209)$, adjusting for differences between women who received $(n=6103)$ and did not receive the Healthy Baby Prenatal Benefit $(n=2106)$ with using propensity score weighting. Using multi-variable regressions, we compared rates of low birth weight, preterm, and small- and large-for-gestational-age births, 5-min Apgar scores, breastfeeding initiation, birth hospitalization length of stay, hospital readmissions, complete vaccination at age one and two, and developmental vulnerability in Kindergarten.

Results: Women who received the benefit had lower risk of low birth weight (adjusted relative risk [aRR] 0.74; 95\% $\mathrm{Cl} 0.62-0.88$ ) and preterm (aRR 0.77; 0.68-0.88) births, and were more likely to initiate breastfeeding (aRR 1.05; $1.01-$ 1.09). Receipt of the Healthy Baby Prenatal Benefit was also associated with higher rates of child vaccination at age one (aRR 1.10; 1.06-1.14) and two (aRR 1.19; 1.13-1.25), and a lower risk that children would be vulnerable in the developmental domains of language and cognitive development (aRR 0.88; 0.79-0.98) and general knowledge/ communication skills (aRR 0.87; 0.77-0.98) in Kindergarten.
\end{abstract}

(Continued on next page)

\footnotetext{
* Correspondence: marni.brownell@umanitoba.ca

${ }^{1}$ Manitoba Centre for Health Policy, Department of Community Health

Sciences, Rady Faculty of Health Sciences, University of Manitoba, 408-727

McDermot Ave, Winnipeg, Manitoba R3E 3P5, Canada

Full list of author information is available at the end of the article
}

C C The Author(s). 2021 Open Access This article is licensed under a Creative Commons Attribution 4.0 International License, which permits use, sharing, adaptation, distribution and reproduction in any medium or format, as long as you give appropriate credit to the original author(s) and the source, provide a link to the Creative Commons licence, and indicate if changes were made. The images or other third party material in this article are included in the article's Creative Commons licence, unless indicated otherwise in a credit line to the material. If material is not included in the article's Creative Commons licence and your intended use is not permitted by statutory regulation or exceeds the permitted use, you will need to obtain permission directly from the copyright holder. To view a copy of this licence, visit http://creativecommons.org/licenses/by/4.0/ The Creative Commons Public Domain Dedication waiver (http://creativecommons.org/publicdomain/zero/1.0/) applies to the data made available in this article, unless otherwise stated in a credit line to the data. 
(Continued from previous page)

Conclusions: A modest unconditional income supplement of CAD \$81/month during pregnancy was associated with improved birth outcomes, increased vaccination rates, and better developmental health outcomes for First Nations children from low-income families.

Keywords: Income supplement, Poverty, Birth outcomes, Early child development, Breastfeeding, Prenatal care, Early development instrument, Indigenous, First Nations

\section{Background}

The prenatal period is the first of several defining life phases that give shape to children's health trajectory. Prenatal exposure to poverty and its correlates, which include higher maternal stress levels, higher likelihood of poor nutrition, and higher rates of smoking and substance use, can have long-lasting consequences for children [1-4]. Women living in poverty during the prenatal period are also more likely to experience adverse birth outcomes (including low birth weight and preterm birth) $[5,6]$, which contribute to many subsequent health, developmental and cognitive challenges as their children grow [7-10]. In recognition of these harmful sequelae, considerable public health efforts continue to attempt to counteract socioeconomic disadvantage among expectant mothers.

Programs providing income supplements (i.e., cash benefits or cash transfers) to low-income pregnant women are an increasingly common initiative, especially in lowand middle-income countries (LMICs) [11]. Eligibility for these income supplements is often conditional upon the expectant mother complying with pre-determined requirements, such as regular visits to a health facility for prenatal care. Well-studied conditional cash transfer programs in LMICs, including the Progresa [12] and Oportunidades [13] programs in Mexico, the Bolsa Familia program in Brazil [14, 15], and the Janani Suraksha Yojana program in India [16], are all associated with improved birth outcomes such as increased birthweight and decreased neonatal/infant mortality [17]. However, income supplement programs for low-income pregnant women living in high-income countries are relatively rare, despite widening health inequities in birth outcomes in many of these places [18].

In Canada, there are significant inequities in many types of health outcomes, including birth outcomes, between Indigenous people ${ }^{1}$ and other Canadians [19]. Understanding the disparities between Indigenous and non-Indigenous people requires an appreciation of the historical, political, societal and economic determinants that influence Indigenous health. For First Nations, these determinants include the multigenerational burden of trauma they carry from forced attendance at residential schools and the harms perpetrated by the 'Sixties Scoop', during which First Nations children were

\footnotetext{
${ }^{1}$ Indigenous Peoples in Canada include First Nations, Inuit and Métis.
}

removed from their own families and placed in predominantly white families, leading to extensive loss of family connections, language and cultural identity [20,21]. Colonial policies and practices have created many other social and economic barriers, which have denied many First Nations access to quality housing, education and employment opportunities, and have made it difficult for them to access healthcare, both for geographical reasons and due to inherent racism and a lack of cultural sensitivity in the healthcare system [22]. Collectively, these challenges make First Nations women and their children more likely than other Canadian women to experience adverse birth and early childhood outcomes; indeed, recent studies show that birth and early childhood outcomes in this population consistently fall well below Canadian norms $[23,24]$. For example, in a populationbased study of First Nations and Inuit birth outcomes in the Canadian province of Quebec, First Nations perinatal and infant mortality rates were 1.5 to 2 times higher than nonIndigenous rates [24]. In Manitoba, First Nations are 1.5 to 2 times more likely to have a preterm or large-for-gestationalage birth, and the likelihood of a First Nations newborn being readmitted to hospital is nearly twice as high as other Manitobans [25]. And in a nationally representative sample of First Nations, Metis and Inuit, First Nations rates of sudden infant death syndrome were reported to be more than seven times higher than in the rest of the Canadian population [23]. Evidence for interventions that can improve birth outcomes among First Nations populations is highly sought after, as evidenced by the Truth and Reconciliation Commission of Canada's Calls to Action, which call upon the federal government to close the gaps in infant and child health outcomes between Indigenous and other Canadians [26].

In Manitoba, which is home to the largest proportion of First Nations people among the Canadian provinces, there is a unique opportunity to evaluate an intervention with the potential to improve birth and early childhood outcomes in this population. The Healthy Baby Prenatal Benefit (HBPB) is an unconditional income supplement available to all low-income pregnant women in Manitoba in their second and third trimesters. To be eligible for the benefit, applicants must provide proof of pregnancy and have an annual income of CAD $\$ 32,000$ or less; once enrolled, they receive a monthly cheque of a maximum amount of CAD $\$ 81 /$ month. Previous research on the whole-of-Manitoba population has shown 
that receipt of the HBPB is associated with improved birth outcomes (fewer low birth weight infants and preterm births, and higher breastfeeding initiation rates) when compared to birth outcomes among low-income mothers who would have been eligible for the benefit but did not apply [27, 28]. However, it is not yet known if the HBPB has the same beneficial effects for First Nations women and their families. The underlying mechanisms that are believed to improve outcomes for lowincome families, such as increasing access to resources and health and social services [29], might not hold true for First Nations families, given the numerous challenges they face. In addition, Indigenous women and children are often under-represented in the health literature [30] - this study, which was undertaken in partnership with researchers from the First Nations Health and Social Secretariat of Manitoba, seeks to recognize and characterize inequities in Indigenous health and bring First Nations voices to the forefront. Our objective was to investigate whether the HBPB was associated with improved birth and early childhood outcomes specifically for Manitoba First Nations women and their children.

\section{Methods}

\section{Study setting}

The study was conducted in Manitoba, Canada (population $\sim 1.4 \mathrm{M}$ ). Manitoba is broadly representative of other Canadian provinces on a number of key health and social indicators [31, 32]. However, Manitoba is unique in offering the $\mathrm{HBPB}$, an unconditional prenatal income supplement for low-income women, and also in having the capacity to link individual-level information on receipt of the HBPB to extensive health and social administrative datasets. The study received approval from the University of Manitoba's Health Research Ethics Board, the government of Manitoba's Health Information Privacy Committee, and the Health Information Research Governance Committee of the Assembly of Manitoba Chiefs.

\section{Data sources}

We used administrative data from the PATHS Data Resource [33], a collection of population-based, individuallevel data describing health status, health service use and social service use for all children born 1984-2014 and registered for universal healthcare in Manitoba, and contained within the Population Research Data Repository at the Manitoba Centre for Health Policy. All records in the Data Repository are stripped of personal information (e.g., names and addresses), but are linkable at the individual level using a scrambled numeric identifier. The Repository data have been used extensively in research and their validity for population studies has been well documented [34, 35]. The specific datasets used in this study are described in Supplementary File 1.

\section{Study cohort}

The study cohort included all First Nations women in Manitoba who had a live birth between 2003 and 2011 and who were eligible to receive the HBPB. We compared First Nations women who applied for and received the benefit (Received $H B P B$ group) to those who were eligible but did not receive the benefit (No HBPB group) (Fig. 1). Women who did not receive the benefit may not have known about the benefit or may have chosen not to apply for it, for example, because they believed they wouldn't be eligible, because they encountered barriers in the application process, or because they were distrustful of the healthcare system or the child welfare system [29].

We formed the cohort by first identifying all women in Manitoba who had a live birth between 2003 and 2011, among whom we identified low-income women using information on receipt of income assistance during their pregnancy. Because income assistance records were used to identify low-income women, and because the province does not keep records of First Nations people living on-reserve who receive federal income assistance, most women living on-reserve were excluded from the study cohort. We also excluded women for whom we did not have data from Manitoba's universal newborn screen; the information collected via the newborn screen (e.g., health-related behaviours like prenatal smoking or alcohol and drug use, and other information on maternal mental health, single parenthood and family functioning - the full list of variables is available in Table 1 and a copy of the screen is available in Supplementary File 2) was required to ensure we could satisfactorily balance characteristics between women who did and did not receive HBPB. Women who had multiple births were excluded due to the greater likelihood of poor health outcomes compared to singleton births. Finally, we selected First Nations women by cross-referencing five different datasets that contain information on First Nations identity: i) the Manitoba First Nations Research File; ii) data from the HBPB application form; iii) data from Manitoba's Families First universal newborn screen; iv) income assistance data; and v) the Early Development Instrument data (full dataset descriptions in Supplementary File 1).

\section{Variables}

Our exposure variable was receipt of HBPB during pregnancy. The amount each family receives is calculated on a sliding scale according to annual family income before taxes. Preliminary analyses demonstrated that nearly all First Nations HBPB recipients in the study cohort received the maximum benefit and so we did not look for a doseresponse effect. Information on birth outcomes (low birth weight, preterm birth, small- or large-for-gestational age, 5 


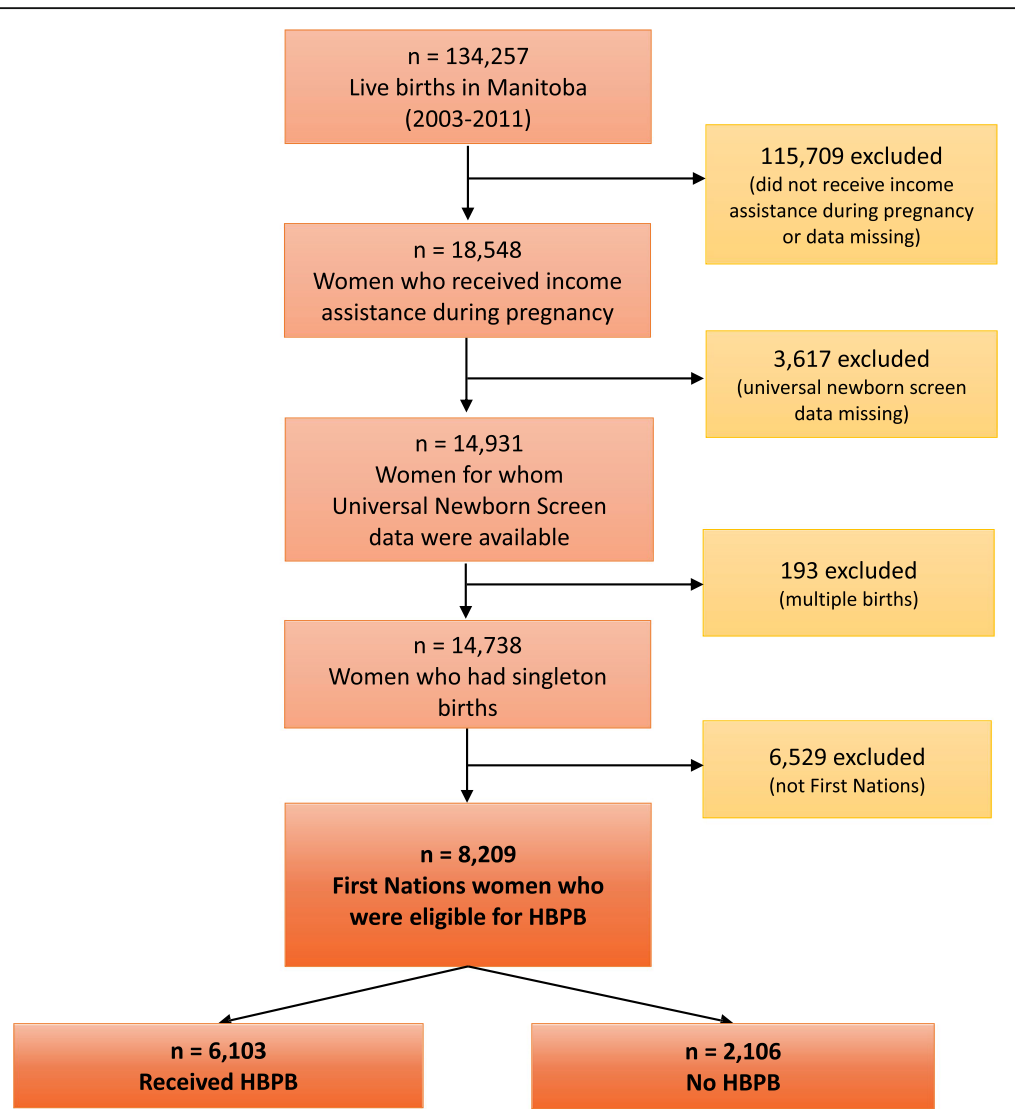

Fig. 1 Study Cohort Development. We identified all Manitoba First Nations mothers with births from 2003 to 2011 who received income assistance during their pregnancies. HBPB: Healthy Baby Prenatal Benefit

min Apgar score, breastfeeding initiation, hospital readmission within 28 days of birth, and length of birth hospitalization) was obtained from hospital discharge abstracts (see Supplementary File 3 for details). Information on early childhood outcomes (childhood immunization at age one and two, and hospital admission in the first 2 years of life) was extracted from the Manitoba Immunization Monitoring System and hospital discharge abstracts, respectively. Developmental vulnerability was measured using the Early Development Instrument, a kindergarten teacher-completed questionnaire that assesses five developmental domains in kindergarten students [36]. Each domain is scored as 'vulnerable' or 'not vulnerable' at the 10th percentile according to national standards $[37,38]$.

We adjusted for potentially confounding variables with information from the universal newborn screen (Table 1). Using methods developed by Rubin (2001), we created propensity scores to adjust for potential systematic differences between the HBPB and No HBPB groups [39]. We used multiple logistic regression to create the propensity scores; receipt of HBPB was the dependent variable and the characteristics in Table 1 were covariates. Each woman's propensity score indicates the probability that she received HBPB given her observed characteristics. From the propensity scores, we then developed inverse probability of treatment weights (IPTWs), which were used to reduce standardized differences between groups [40, 41].

\section{Statistical analyses}

We ran generalized linear models with a binomial distribution for each of the dichotomous outcomes, and used the log-link function to estimate crude and IPTWadjusted risk ratios associated with receiving HBPB. For continuous outcomes (birth hospitalization length of stay), we ran generalized linear models with a negative binomial distribution, and used the log-link function to estimate the mean length of stay associated with receiving HBPB by modeling the crude (unweighted) and IPTW-adjusted means. We measured sensitivity to unmeasured confounding using a gamma sensitivity test, which estimates the strength of any unmeasured confounder required to nullify statistically significant results [42].

Population-attributable fractions (PAFs) and populationpreventable fractions (PPFs) were calculated to quantify the impact of the HBPB [43]. Where HBPB was associated with an increase in the outcome, we used the following formula: $\mathrm{PAF}=\mathrm{Pe} \times[(\mathrm{RR}-1) / \mathrm{RR}]$, where Pe is prevalence of the exposure. Where HBPB was associated with a reduction in the 
Table 1 Characteristics of Low-Income First Nations Women before and after Propensity Score Weighting

\begin{tabular}{|c|c|c|c|c|c|}
\hline & $\begin{array}{l}\text { Received HBPB } \\
n=6103\end{array}$ & $\begin{array}{l}\text { No HBPB } \\
n=2106\end{array}$ & $P$ & $\begin{array}{l}\text { Standardized Diff } \\
\text { Before Weighting }\end{array}$ & $\begin{array}{l}\text { Standardized Diff } \\
\text { After Weighting }\end{array}$ \\
\hline Universal newborn screen completed prenatally ${ }^{a}(\%)$ & 10.73 & 6.41 & $<0.001$ & 4.32 & 0.00 \\
\hline Alcohol or substance use during pregnancy (\%) & 36.41 & 38.37 & 0.110 & 1.96 & 0.00 \\
\hline Smoked during pregnancy (\%) & 56.37 & 59.83 & 0.005 & 3.46 & 0.00 \\
\hline Did not complete high school (\%) & 59.07 & 58.59 & 0.703 & 0.48 & 0.01 \\
\hline Single parent family (\%) & 51.07 & 45.25 & $<0.001$ & 5.82 & 0.00 \\
\hline No prenatal care before 6 months (\%) & 8.67 & 17.90 & $<0.001$ & 9.23 & 0.00 \\
\hline Has mood or anxiety disorder (\%) & 23.63 & 19.37 & $<0.001$ & 4.26 & 0.00 \\
\hline Has schizophrenia (\%) & 0.88 & 0.66 & 0.303 & 0.22 & 0.01 \\
\hline Has a mental disability (\%) & 1.21 & 1.19 & 0.926 & 0.02 & 0.00 \\
\hline Family history of disability (\%) & 3.41 & 3.70 & 0.532 & 0.29 & 0.01 \\
\hline Father is antisocial (\%) & 5.21 & 4.23 & 0.060 & 0.98 & 0.01 \\
\hline Mother is antisocial (\%) & 2.11 & 2.61 & 0.206 & 0.50 & 0.01 \\
\hline Current substance use (\%) & 3.60 & 4.51 & 0.076 & 0.91 & 0.00 \\
\hline Social isolation (\%) & 6.77 & 7.74 & 0.144 & 0.97 & 0.00 \\
\hline Relationship distress (\%) & 16.24 & 14.62 & 0.074 & 1.62 & 0.01 \\
\hline Violence between parents (\%) & 9.27 & 8.31 & 0.172 & 0.96 & 0.01 \\
\hline Abused as a child (\%) & 20.27 & 17.33 & 0.003 & 2.94 & 0.01 \\
\hline Has diabetes (\%) & 3.24 & 1.76 & $<0.001$ & 1.48 & 0.00 \\
\hline Family lives on reserve (\%) & 2.64 & 4.61 & $<0.001$ & 1.97 & 0.00 \\
\hline \multicolumn{6}{|l|}{ Age at first birth } \\
\hline Count & 6103 & 2106 & & & \\
\hline Mean & 18.7 & 18.5 & 0.013 & 0.20 & 0.01 \\
\hline \multicolumn{6}{|l|}{ Area-level SES index (higher value $=$ lower SES) } \\
\hline Count & 6098 & 2104 & & & \\
\hline Mean & 1.1 & 1.0 & $<0.001$ & 0.10 & 0.00 \\
\hline
\end{tabular}

${ }^{a}$ Families First screens are typically completed postnatally, so when a screen is completed prenatally, this indicates the presence of additional risk factors. $H B P B$ Healthy Baby Prenatal Benefit, SES socioeconomic status

outcomes, we used: $\mathrm{PPF}=\mathrm{Pe} \times(1-\mathrm{RR})$. Confidence intervals were calculated using the standard deviation of a bootstrapped mean PAF or PPF derived from 500 samples of the population.

\section{Results}

The final study cohort included 8209 First Nations women who gave birth to live singleton infants between 2003 and 2011, who received income assistance during their pregnancy, and for whom we had data from the universal newborn screen. Among these, 6103 women received the $\mathrm{HBPB}$, while 2106 women did not receive the benefit (Fig. 1). The women's individual and family characteristics are shown in Table 1 . We initially observed some significant differences between the two groups on several characteristics. For example, women in the Received $H B P B$ group were more likely to be single parents than women in the $N o H B P B$ group, whereas women in the No $H B P B$ group were more likely to have reported that they smoked during their pregnancy than women in the Received $H B P B$ group. After applying the IPTWs, all the covariates' standardized differences dropped to $0.01 \%$ or less, indicating that the groups' characteristics were satisfactorily balanced [44].

In Table 2, we present the crude rates, unweighted means and adjusted risk ratios of birth outcomes among First Nations infants whose mothers did or did not receive HBPB. Receiving HBPB was associated with a significant reduction in low birth weight and preterm births, and a significant increase in breastfeeding initiation. There was no association between HBPB and small-for-gestational-age or large-for-gestational-age births, low 5-min Apgar scores, hospital readmission within 28 days of the birth, or length of hospital stay following birth. For low birth weight births and preterm births, the $\gamma$ sensitivity values of $>40$ indicate that the findings are robust to unmeasured confounding. This means that in addition to the confounders we adjusted 
Table 2 Association between Healthy Baby Prenatal Benefit (HBPB) and Birth Outcomes for First Nations Mothers and Infants

\begin{tabular}{|c|c|c|c|c|c|c|c|c|}
\hline \multirow[t]{2}{*}{ Outcome } & \multicolumn{2}{|l|}{$n$} & \multicolumn{2}{|c|}{$\begin{array}{l}\text { Crude Rates } \\
\text { (\%) }\end{array}$} & \multirow[t]{2}{*}{$\begin{array}{l}\text { Adjusted Risk } \\
\text { Ratio }\end{array}$} & \multirow[t]{2}{*}{$95 \% \mathrm{Cl}$} & \multirow[t]{2}{*}{$P$} & \multirow[t]{2}{*}{$\begin{array}{l}\text { Y Sensitivity } \\
\text { Value }^{a}\end{array}$} \\
\hline & HBPB & $\begin{array}{l}\text { No } \\
\text { HBPB }\end{array}$ & HBPB & $\begin{array}{l}\text { No } \\
\text { HBPB }\end{array}$ & & & & \\
\hline Low Birth Weight & 302 & 151 & 4.95 & 7.17 & 0.741 & $0.621,0.883$ & $\begin{array}{l}< \\
0.001\end{array}$ & 41.2 \\
\hline Preterm Birth & 537 & 249 & 8.80 & 11.82 & 0.774 & $0.679,0.883$ & $\begin{array}{l}< \\
0.001\end{array}$ & 48.5 \\
\hline Small for Gestational Age & 402 & 162 & 6.59 & 7.70 & 0.916 & $0.781,1.073$ & 0.276 & - \\
\hline Large for Gestational Age & 1216 & 367 & 19.93 & 17.45 & 1.069 & $0.976,1.170$ & 0.151 & - \\
\hline Low 5-min Apgar Score & 183 & 69 & 3.00 & 3.28 & 0.870 & $0.681,1.111$ & 0.265 & - \\
\hline Breastfeeding Initiation & 3765 & 1191 & 61.72 & 56.55 & 1.046 & $1.009,1.085$ & 0.014 & 20.1 \\
\hline Hospital Readmission within 28 Days & 159 & 43 & 2.76 & 2.22 & 1.163 & $0.871,1.554$ & 0.306 & - \\
\hline \multirow[t]{2}{*}{ Outcome } & \multicolumn{2}{|l|}{$n$} & \multicolumn{2}{|c|}{$\begin{array}{l}\text { Unweighted } \\
\text { Means }\end{array}$} & \multicolumn{2}{|c|}{ Weighted Means (95\% Cl) } & $P$ & $\begin{array}{l}\text { Y Sensitivity } \\
\text { Value }\end{array}$ \\
\hline & HBPB & $\begin{array}{l}\text { No } \\
\text { HBPB }\end{array}$ & HBPB & $\begin{array}{l}\text { No } \\
\text { HBPB }\end{array}$ & HBPB & No HBPB & & \\
\hline $\begin{array}{l}\text { Birth Hospitalization LOS in days (for vaginal } \\
\text { births only) }\end{array}$ & 5260 & 1796 & 2.96 & 3.05 & $2.96(2.87,3.04)$ & $\begin{array}{l}3.04(2.93 \\
3.15)\end{array}$ & 0.239 & - \\
\hline
\end{tabular}

${ }^{a}$ The $y$ sensitivity analyses were conducted only for findings that were statistically significant. HBPB Healthy Baby Prenatal Benefit, LOS length of stay

for in the propensity score, any unmeasured confounder would need to both correctly predict receipt of HBPB and account for $\sim 40-50 \%$ of the relationship between receipt of $\mathrm{HBPB}$ and these two outcomes; the likelihood of such a confounder existing is very small. The robustness of the findings for breastfeeding initiation (with a $\gamma$ sensitivity value of 20.1) could be somewhat more sensitive to unmeasured confounding.

Table 3 presents the crude rates and adjusted risk ratios of early childhood outcomes among First Nations children whose mothers did or did not receive HBPB. Receiving HBPB was associated with a significantly higher likelihood of children having a complete set of immunizations at age 1 and 2, and a significantly lower likelihood that children would be developmentally vulnerable in the domains of 'language and cognitive development' and 'general knowledge and communication skills' in kindergarten. There was no association between HBPB and hospital admission in the child's first 2 years of life or for any of the other three developmental domains on the Early Development Instrument. For the immunization outcomes, the $\gamma$ sensitivity values of $>60$ indicate that the findings are robust to unmeasured confounding. In addition to adjusting for the confounders in the propensity score, any unmeasured confounder would need to both correctly predict receipt of HBPB and account for $\sim 60-70 \%$ of the relationship between receipt of $\mathrm{HBPB}$ and these outcomes; and again, the likelihood of such a confounder existing is very small. The robustness of the findings for developmental vulnerability at Kindergarten (with $\gamma$ sensitivity values of 11.0-13.6) is somewhat more likely to be sensitive to unmeasured confounding.
Figure 2 illustrates the PAF for breastfeeding initiation (3\%, although the error bars indicate that this was not statistically significant), and complete childhood vaccination at age 1 and 2 (6.6 and 11.8\%, respectively). The PPF for low birth weight was $19.3 \%$, for preterm birth was $16.8 \%$, and for developmental vulnerability at kindergarten was 9.2\% (for language and cognitive development) and 9.8\% (for general knowledge and communication skills).

\section{Discussion}

This retrospective cohort study on a prenatal income supplement provided to low-income First Nations women demonstrates improvements in several birth and early childhood outcomes. Receiving the HBPB was associated with reductions in low birth weight births and preterm births, translating into $19 \%$ of low birth weight births and almost $17 \%$ of preterm births prevented among First Nations women. As well, receiving the HBPB was associated with a higher likelihood of First Nations children receiving a complete series of vaccinations at age 1 and 2, of which 6.6 and 11.8\% (respectively) can be attributed to the benefit.

The finding that a prenatal income supplement of only CAD $\$ 81 /$ month is associated with improved birth outcomes is remarkable, given that it is well known that influencing clinical outcomes within lower socioeconomic conditions has proven very difficult. Many public discourses and policy interventions focus attention on the individual behaviours of pregnant women (such as diet and exercise) [45], but in a real-world context that recognizes the close relationship between low socioeconomic status and disparities in health, the fundamental 
Table 3 Association between Healthy Baby Prenatal Benefit (HBPB) and Early Childhood Outcomes among First Nations Children

\begin{tabular}{|c|c|c|c|c|c|c|c|c|}
\hline \multirow[t]{2}{*}{ Outcome } & \multicolumn{2}{|l|}{$n$} & \multicolumn{2}{|c|}{ Crude Rates (\%) } & \multirow{2}{*}{$\begin{array}{l}\text { Adjusted } \\
\text { Risk } \\
\text { Ratio }\end{array}$} & \multirow[t]{2}{*}{$95 \% \mathrm{Cl}$} & \multirow[t]{2}{*}{$P$} & \multirow{2}{*}{$\begin{array}{l}\text { Y } \\
\text { Sensitivity } \\
\text { Value }\end{array}$} \\
\hline & HBPB & No HBPB & HBPB & No HBPB & & & & \\
\hline Complete Childhood Vaccinations (Age 1) & 4063 & 1240 & 67.48 & 60.14 & 1.097 & $1.059,1.137$ & $<0.001$ & 61.6 \\
\hline Complete Childhood Vaccinations (Age 2) & 2964 & 852 & 49.79 & 41.74 & 1.189 & $1.130,1.250$ & $<0.001$ & 70.9 \\
\hline Hospital Readmission before Age 2 & 1166 & 410 & 42.10 & 41.45 & 0.979 & $0.893,1.073$ & 0.648 & - \\
\hline \multicolumn{9}{|l|}{ Developmental Vulnerability at Kindergarten } \\
\hline Physical Health and Well-Being & 658 & 230 & 30.45 & 33.00 & 0.927 & $0.831,1.034$ & 0.173 & - \\
\hline Social Competence & 579 & 172 & 26.78 & 24.68 & 1.075 & $0.948,1.219$ & 0.262 & - \\
\hline Emotional Maturity & 467 & 143 & 21.61 & 20.58 & 1.030 & $0.892,1.188$ & 0.690 & - \\
\hline Language and Cognitive Development & 619 & 226 & 28.64 & 32.42 & 0.879 & $0.786,0.983$ & 0.023 & 13.6 \\
\hline Communication Skills and General Knowledge & 531 & 191 & 24.56 & 27.40 & 0.870 & $0.769,0.984$ & 0.027 & 11.3 \\
\hline One or more domains & 1180 & 387 & 54.58 & 55.52 & 0.982 & $0.919,1.050$ & 0.595 & - \\
\hline
\end{tabular}

EDI Early Development Instrument, $H B P B$ Healthy Baby Prenatal Benefit

causes of adverse health outcomes must be addressed if there is to be any hope of improving birth outcomes at the population level. This perspective is emphasized by Hughes and Simpson (1995), who argue that reducing persistent disparities in low birth weight requires embracing a broader definition of health that incorporates multiple social dimensions [46]. Further evidence on the mechanisms by which an unconditional prenatal income supplement can bring about improved clinical outcomes is presented by Struthers et al. [29], who interviewed recipients of the HBPB about what they used the benefit for and how it impacted them. Participants in that study described how the money helped them purchase items to prepare for the birth of their child, improve their nutrition, and engage in self-care behaviours that reduced their stress. Given these findings and the results of other cash transfer programs [12-16], and taking into account the large health inequities in birth outcomes between First Nations and other Canadians [47-49], there is a clear need to ensure adequate investment in resources for low income First Nations women and their families. Notably, in the nearly 20 years the HBPB has been available, the amount of the benefit has not increased at all. Whether more money could result in even better outcomes remains to be investigated.

Another important finding of the study was that First Nations children whose families received the HBPB were more likely than children from families who did not receive the benefit to have all of the recommended vaccinations at age one and age two. Vaccination is a vital component of preventive healthcare in young children that depends on high levels of coverage. While vaccination rates among First Nations children, particularly those living on-reserve, used to be lower than the

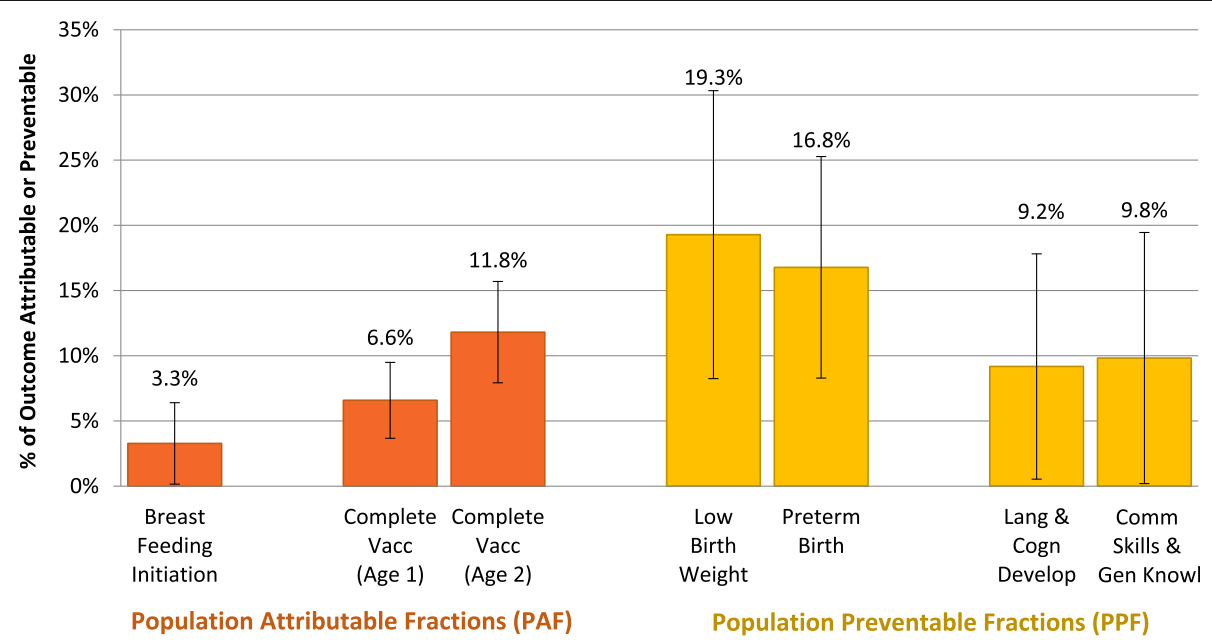

Fig. 2 Population Attributable and Population Preventable Fractions of Outcomes Associated with the Healthy Baby Prenatal Benefit. Vacc: vaccination; Lang \& Cogn Develop: language and cognitive development score on the Early Development Instrument; Comm Skills \& Gen Knowl: communication skills and general knowledge score on the Early Development Instrument 
general Canadian population [50], recent data suggest that the percent of First Nations infants and children who are fully vaccinated has increased in recent years and is not substantially different from average provincial and national estimates in Canada [51]. However, the percentage of children who are fully vaccinated by age 2 still remains well below the target of $95 \%$ in many jurisdictions, including Manitoba. Many First Nations mothers recognize the importance of vaccines in preventing childhood disease, but some families may be hesitant to have their children vaccinated because of a history of negative interactions with the healthcare system, or because of difficulty accessing a clinic [50]. Families living in rural or remote communities may not have a health centre nearby, and some clinics may have staffing shortages and high rates of turnover, further disrupting health service delivery and monitoring of public health measures like vaccination [52]. In the context of our study, the HBPB may seem like an unlikely public health strategy for increasing vaccination rates; however, we speculate that the benefit, and the larger Healthy Baby program of which it is a component, could play a role in connecting families to primary care providers during and after pregnancy, and this may contribute to ensuring that First Nations children are protected from vaccinepreventable illnesses.

Our study's findings on the Early Development Instrument scores showed that First Nations children whose families received the HBPB were less likely to be developmentally vulnerable (in two developmental domains) when they entered kindergarten. It is notable that the two domains recipients of the HBPB were stronger in, 'language \& cognitive development' and 'general knowledge \& communication skills', are closely tied to academic achievement. Whether it is plausible that CAD $\$ 81 /$ month during the latter two trimesters of a lowincome woman's pregnancy can have an impact on their child's readiness for school is open to speculation however, a clear gradient between household income and a child's developmental vulnerability has been observed [53], and the HBPB represented a significant increase of about $10 \%$ in recipients' average income. Another explanation for these findings is that, as the relatively low gamma sensitivity values for these outcomes indicate, there are other unmeasured factors at play that we were not able to account for in our analysis. The association between receiving the HBPB and being less likely to be developmentally vulnerable may only reflect the fact that some low-income households eligible for the benefit are already well-connected to health and social services and are providing high quality parenting to their young children during the early years - this is however a difficult concept to measure using administrative data.

\section{Strengths and limitations}

Elements of our study design, including use of the comprehensive population-based Manitoba Population Research Data Repository to identify eligible First Nations women who were and were not receiving the $\mathrm{HBPB}$, and use of IPTW and $\gamma$ sensitivity analyses to balance the study groups and strengthen our confidence in the comparisons drawn between them, are strengths of this study. Using administrative data also allowed us to avoid problems associated with reporting and recall biases [54].

Despite these strengths, we were limited by potentially confounding factors that the data and our efforts to minimize bias could not account for. Although our use of propensity scoring minimized differences between the two study groups, there is still potential for selection bias in our study design due to intrinsic differences in the women who apply for the HBPB and those who do not. Some of the reasons why Manitoba women may not apply for the benefit were explored previously [29]. Another important limitation of the study was the need to limit the study cohort to women receiving provincial income assistance because we did not have access to the whole-population information on family income needed to calculate national measures like the Low Income Measure (LIM) or the Low Income Cut-Off (LICO). Our approach ensured that women in both study groups had equally low incomes, but we recognize that focusing on this very low income group may limit the generalizability of our findings. Our decision to limit the study cohort to women receiving income assistance also meant that we excluded most First Nations women living on-reserve, because income assistance data in Manitoba are only available for First Nations residents living off-reserve. Although we found that First Nations women living on reserve made up less than $40 \%$ of all First Nations women who gave birth during the study period, and that only $56 \%$ of these women applied for the $\mathrm{HBPB}$, there are significant differences in health outcomes and income levels between women living on and off reserve that could influence the results of this study. A recent study on the health status of Manitoba First Nations reports that individuals living on reserve have higher premature mortality rates, lower rates of primary care visits but higher rates of hospitalization, and higher rates of mood and anxiety disorders compared to individuals living off reserve [55]. Data from the Canada Census and self-reported household income data place the majority of First Nations people living on-reserve in the lowest income quintiles and categories, compared to other Manitobans [55, 56]. Given the health and income disparities between those living on and off reserve, were we to include women living on reserve in future analyses, the HBPB would likely be associated with even more robust improvements in outcomes in this population. 


\section{Conclusion}

This study showed that the Healthy Baby Prenatal Benefit, an unconditional monthly benefit provided to low-income First Nations women during pregnancy, was associated with improved birth outcomes, higher rates of child vaccination, and a higher likelihood that kindergarten-aged children would be better prepared for school entry. That this population-level intervention was associated with better outcomes from infanthood through early childhood is remarkable, demonstrating how even modest financial support provided directly to First Nations families experiencing poverty without any "strings attached" can contribute to an upwards trajectory. The study findings align with what advocates have been saying for many years - that at least part of the solution to poverty is simply to provide sufficient resources to families experiencing poverty and allow them to determine how they should be used.

\section{Abbreviations}

HBPB: Healthy Baby Prenatal Benefit; IPTW: Inverse Probability Treatment Weight; LICO: Low Income Cut-Off; LIM: Low Income Measure; LMIC: Low and Middle Income Countries; PAF: Population Attributable Fraction; PPF: Population Preventable Fraction

\section{Supplementary Information}

The online version contains supplementary material available at https://doi. org/10.1186/s12884-021-03782-w.

Additional file 1: Supplementary File 1. List of Datasets from the Manitoba Population Research Data Repository. Supplementary File 2. Families First Screening Form. Supplementary File 3. List of Study Outcomes

\section{Acknowledgements}

We acknowledge the Manitoba government agencies and departments that provided the data used to conduct this study, including Manitoba Health, Seniors and Active Living, Manitoba Families, and the Winnipeg Regional Health Authority. The results and conclusions are those of the authors, and no official endorsement by the data providers is intended or should be inferred.

\footnotetext{
Authors' contributions

Conceptualization: Marni Brownell, Jennifer Enns, Nathan Nickel, Dan Chateau, Mariette Chartier, Rob Santos, Alan Katz. Data curation: Marni Brownell. Formal analysis: Joykrishna Sarkar. Funding acquisition: Marni Brownell, Jennifer Enns, Nathan Nickel, Dan Chateau, Mariette Chartier. Investigation: Marni Brownell, Jennifer Enns, Nathan Nickel, Dan Chateau, Mariette Chartier, Rhonda Campbell, Wanda Phillips-Beck, Elaine Burland, Joykrishna Sarkar, Rob Santos, Alan Katz. Methodology: Marni Brownell, Jennifer Enns, Nathan Nickel, Dan Chateau, Mariette Chartier. Project administration: Marni Brownell, Elaine Burland. Resources: Marni Brownell. Software: Marni Brownell. Supervision: Marni Brownell. Validation: Joykrishna Sarkar, Nathan Nickel. Visualisation: Joykrishna Sarkar, Jennifer Enns. Writing - original draft: Jennifer Enns, Marni Brownell. Writing - review \& editing: Jennifer Enns and all other authors. The author(s) read and approved the final manuscript.

Funding

This work was supported by a Canadian Institutes of Health Research Operating Grant in Population Health Intervention Research to Promote Health and Health Equity, with sponsorship from the Institute of Population and Public Health and the CIHR Pathways to Health Equity for Aboriginal Peoples Initiative in partnership with the Saskatchewan Health Research Foundation (grant number Gl1-145122). The funders had no role in data collection, analysis, or interpretation; trial design; patient recruitment; or any
}

aspect pertinent to the study. The results and conclusions are those of the authors, and no official endorsement by the funders is intended or should be inferred. All authors had full access to the full data in the study and accept responsibility to submit for publication.

\section{Availability of data and materials}

Data used in this study were derived from administrative health and social data as a secondary use. The data were provided to the Manitoba Centre for Health Policy (MCHP) under specific data sharing agreements only for approved use at MCHP. The original source data is not owned by the researchers or MCHP and as such cannot be provided to a public repository. However, the original data source and approval for use have been noted in the acknowledgments of the article, and where necessary, source data specific to this article or project may be reviewed at MCHP with the consent of the original data providers, along with the required privacy and ethical review bodies' approval.

\section{Declarations}

Ethics approval and consent to participate

The study was conducted in accordance with the authors' institution's guidelines for ethical conduct of research. The study proposal was reviewed and approved by the University of Manitoba Health Research Ethics Board (HREB HS20783 - H2017:155) and the Health Information Research Government Committee (HIRGC) of the Assembly of Manitoba Chiefs. The Manitoba Government's Health Information Privacy Committee (HIPC \#2017/ 2018-50) also reviewed the proposal and waived the requirement for individual informed consent on the basis that the study used de-identified administrative data, none of the participants were directly involved in the study and there was low risk of any individual being personally identified. See related files for HREB, HIRGC and HIPC approvals.

\section{Consent for publication}

Not applicable.

\section{Competing interests}

The authors declare that they have no competing interests.

\section{Author details}

${ }^{1}$ Manitoba Centre for Health Policy, Department of Community Health Sciences, Rady Faculty of Health Sciences, University of Manitoba, 408-727 McDermot Ave, Winnipeg, Manitoba R3E 3P5, Canada. ${ }^{2}$ First Nations Health and Social Secretariat of Manitoba, Winnipeg, Canada. ${ }^{3}$ Department of Family Medicine, Rady Faculty of Health Sciences, University of Manitoba, Winnipeg, Canada.

Received: 28 January 2021 Accepted: 30 March 2021

Published online: 20 April 2021

\section{References}

1. Séguin L, Nikiéma B, Gauvin L, Zunzunegui M, Xu Q. Duration of poverty and child health in the Quebec longitudinal study of child development: longitudinal analysis of a birth cohort. Pediatrics. 2007;119(5):e1063-70. https://doi.org/10.1542/peds.2006-1750.

2. Vaivada T, Gaffey M, Das J, Bhutta Z. Evidence-based interventions for improvement of maternal and child nutrition in low-income settings: what's new? Curr Opin Clin Nutr Metab Care. 2017;20(3):204-10. https://doi.org/1 $0.1097 /$ MCO.0000000000000365.

3. Blair C, Raver CC. Poverty, stress, and brain development: new directions for prevention and intervention. Acad Pediatr. 2016 Apr;16(3 Suppl):S30-6. https://doi.org/10.1016/j.acap.2016.01.010

4. Hair N, Hanson J, Wolfe B, Pollak S. Association of child poverty, brain development, and academic achievement. JAMA Pediatr. 2015;169(9):822-9. https://doi.org/10.1001/jamapediatrics.2015.1475

5. Kramer M, Séguin L, Lyson J, Goulet L. Socioeconomic disparities in pregnancy outcome: why do the poor fare so poorly? Paediatr Perinat Epidemiol. 2000; 14(3):194-210. https://doi.org/10.1046/j.1365-3016.2000.00266.x

6. Blumenshine P, Egerter S, Barclay CJ, Cubbin C, Braveman PA. Socioeconomic disparities in adverse birth outcomes: a systematic review. Am J Prev Med. 2010;39(3):263-72. https:/doi.org/10.1016/j.amepre.2010.05.012. 
7. Bowen J, Gibson F, Hand P. Educational outcome at 8 years for children who were born extremely prematurely: a controlled study. J Paediatr Child Health. 2002;38(5):438-44. https://doi.org/10.1046/j.1440-1754.2002.00039.x.

8. Jennische $M$, Sedin $G$. Speech and language skills in children who required neonatal intensive care: evaluation at $6.5 \mathrm{y}$ of age based on interviews with parents. Acta Paediatr. 1999;88(9):975-82. https://doi.org/10.1111/j.1651-222 7.1999.tb00193.x

9. McCarton C, Wallace I, Divon M, Vaughan H Jr. Cognitive and neurologic development of the premature, small for gestational age infant through age 6: comparison by birth weight and gestational age. Pediatrics. 1996;98(6 Pt 1):1167-78.

10. Yang $S$, Platt R, Kramer M. Variation in child cognitive ability by week of gestation among healthy term births. Am J Epidemiol. 2010;171(4):399-406. https://doi.org/10.1093/aje/kwp413.

11. Department for International Development. Cash Transfers: Evidence Paper. London; 2011. Available from: https://www.who.int/alliance-hpsr/allia ncehpsr_dfidevidencepaper.pdf. Accessed 13 Apr 2021.

12. Barham T. A healthier start: the effect of conditional cash transfers on neonatal and infant mortality in rural Mexico. J Dev Econ. 2011;94:74-85.

13. Barber S, Gertler P. Empowering women: how Mexico's conditional cash transfer programme raised prenatal care quality and birth weight. J Dev Eff. 2010;2:51-73.

14. Shei A. Brazil's conditional cash transfer program associated with declines in infant mortality rates. Health Aff. 2013;32(7):1274-81. https://doi.org/10.1377/ hlthaff.2012.0827.

15. Guanais F. The combined effects of the expansion of primary health care and conditional cash transfers on infant mortality in Brazil. Am J Public Health. 2013;103(11):2000-6. https://doi.org/10.2105/AJPH.2013.301452.

16. Lim S, Dandona L, Hoisington J, James S, Hogan M, Gakidow E. India's Janani Suraksha Yojana, a conditional cash transfer programme to increase births in health facilities: an impact evaluation. Lancet. 2010; 375:2009-23.

17. Cruz R, Moura L, Soares NJ. Conditional cash transfers and the creation of equal opportunities of health for children in low and middle-income countries: a literature review. Int J Equity Health. 2017;16(1):161. https://doi. org/10.1186/s12939-017-0647-2

18. Kim D, Saada A. The social determinants of infant mortality and birth outcomes in western developed nations: a cross-country systematic review. Int J Environ Res Public Health. 2013;10(6):2296-335. https://doi.org/10.3390/ ijerph10062296.

19. The Pan-Canadian Public Health Network. Key Health Inequalities in Canada: A National Portrait. Ottawa: The Public Health Agency of Canada. 2018. https://www.canada.ca/content/dam/phac-aspc/documents/services/publica tions/science-research/key-health-inequalities-canada-national-portraitexecutive-summary/key_health_inequalities_full_report-eng.pdf. Accessed 13 Apr 2021

20. Gracey $M$, King M. Indigenous health part 1: determinants and disease pattern. Lancet. 2009;374(9683):65-75. https://doi.org/10.1016/S0140-673 6(09)60914-4.

21. King $M$, Smith $A$, Gracey $M$. Indigenous health part 2: the underlying causes of the health gap. Lancet. 2009;374(9683):76-85. https://doi.org/10.1016/ S0140-6736(09)60827-8.

22. Reading C. Structural determinants of Aboriginal peoples' health. In: Greenwodd M, de Leeuw S, Lindsay N, Reading C, editors. Determinants of indigenous peoples' health in Canada: beyond the social. Toronto: Canadian Scholars' Press; 2015

23. Sheppard A, Shapiro G, Bushnik T, Wilkins R, Perry S, Kaufman J, et al. Birth outcomes among first nations, Inuit and Métis populations. Ottawa; 2017. Available from: https://www150.statcan.gc.ca/n1/en/pub/82-003-x/201 7011/article/54886-eng.pdf?st=LqUbROUw. Accessed 13 Apr 2021

24. Chen L, Xiao L, Auger N, Torrie J, McHugh N, Zoungrana H, et al. Disparities and Trends in Birth Outcomes, Perinatal and Infant Mortality in Aboriginal vs. Non-Aboriginal Populations: A Population-Based Study in Quebec, Canada 1996-2010. PLoS One. 2015;10(9):e0138562.

25. Chartier M, Brownell M, Star L, Murdock N, Campbell R, Pillips-Beck W, et al. Our children, our future: the health and well-being of first nations children in Manitoba. Winnipeg; 2020. Available from: http://mchp-appserv.cpe.uma nitoba.ca/reference/FNKids_Report_Web.pdf. Accessed 13 Apr 2021.

26. Truth and Reconciliation Commission of Canada. Calls to Action. Winnipeg; 2015. Available from: http://trc.ca/assets/pdf/Calls_to_Action_English2.pdf. Accessed 13 Apr 2021
27. Brownell M, Chartier M, Nickel N, Chateau D, Martens P, Sarkar J, et al. Unconditional prenatal income supplement and birth outcomes. Pediatr. 2016;137(6):e20152992. https://doi.org/10.1542/peds.2015-2992.

28. Brownell M, Nickel N, Chartier M, Enns J, Chateau D, Sarkar J, et al. An unconditional prenatal income supplement reduces population inequities in birth outcomes. Health Aff. 2018 Feb 1;37(3):447-55. https://doi.org/10.1377/ hlthaff.2017.1290.

29. Struthers A, Metge C, Charette C, Enns JE, Nickel NC, Chateau D, et al. Understanding the Particularities of an Unconditional Prenatal Cash Benefit for Low-Income Women: A Case Study Approach. Inq J Health Care Organ Provision Financ. 2019. https://doi.org/10.1177/0046958019870967.

30. Kumar M, Wesche S, McGuire C. Trends in Métis-related health research (1980-2009): identification of research gaps. Can J Public Health. 2012;103(1): 23-8. https://doi.org/10.1007/BF03404064.

31. Oreopoulos P, Stabile M, Walld R, Roos L. Short-medium, and long term consequences of poor infant health: an analysis using siblings and twins. J Hum Resour. 2008;43:88-138.

32. O'Grady K, Deussing M, Scerbina T, Fund K, Muhe N. Measuring up: Canadian Results of the OECD PISA study. Canada: Council of Ministers of Education; 2016. http://cmec.ca/Publications/Lists/Publications/Atta chments/365/Book_PISA2015_EN_Dec5.pdf

33. Nickel NC, Chateau DG, Martens PJPJ, Brownell MD, Katz A, Burland EMJ, et al. Data Resource Profile: Pathways to Health and Social Equity for Children (PATHS Equity for Children). Int J Epidemiol. 2014;43(5):1438-49.

34. Roos LL, Menec V, Currie RJ. Policy analysis in an information-rich environment. Soc Sci Med. 2004 Jun;58(11):2231-41. https://doi.org/10.1016/ j.socscimed.2003.08.008.

35. Roos LL, Gupta S, Soodeen RA, Jebamani L. Data quality in an informationrich environment: Canada as an example. Can J Aging. 2005;24(Suppl 1): 153-70. https://doi.org/10.1353/cja.2005.0055.

36. Guhn M, Janus M, Hertzman C. The early development instrument: translating school readiness assessment into community actions and policy planning. Early Educ Dev. 2007;18(3):369-74. https://doi.org/10.1080/104092 80701610622.

37. Janus M, Brick SA, Duku ER. Validity and psychometric properties of the early development instrument in Canada, Australia, United States and Jamaica. Soc Indic Res. 2011;103(2):283-97. https://doi.org/10.1007/s11205011-9846-1.

38. Guhn M, Zumbo BD, Janus M, Hertzman C. Validation theory and research for a population-level measure of children's development, wellbeing, and school readiness. Soc Indic Res. 2011;103(2):183-91. https://doi.org/10.1007/ s11205-011-9841-6.

39. Rubin DB. Using propensity scores to help design observational studies: application to the tobacco litigation. Health Serv Outcome Res Methodol. 2001;2(3/4):169-88. https://doi.org/10.1023/A:1020363010465.

40. Guo S, Fraser MW. Propensity score analysis: statistical methods and applications. Thousand Oaks: Sage Publications; 2009.

41. Austin P. Balance diagnostics for comparing the distribution of baseline covariates between treatment groups in propensity-score matched samples. Stat Med. 2009;28(25):3083-107. https://doi.org/10.1002/sim.3697.

42. Rosenbaum P. Observational studies. New York: Springer-Verlag New York Inc; 2010. https://doi.org/10.1007/978-1-4419-1213-8.

43. Rockhill B, Newman B, Weinberg C. Use and misuse of population attributable fractions. Am J Public Health. 1998;88(1):15-9. https://doi.org/1 0.2105/AJPH.88.1.15.

44. Austin PC. An introduction to propensity score methods for reducing the effects of confounding in observational studies. Multivar Behav Res. 2011; 46(3):399-424. https://doi.org/10.1080/00273171.2011.568786.

45. Campbell EE, Seabrook JA. The influence of socioeconomic status on adverse birth outcomes. Can J Midwifery Res Pract. 2016;15(2):10-20.

46. Hughes D, Simpson L. The role of social change in preventing low birth weight. The Future of Children. Low Birth Weight (Spring). 1995; 5(1):87-102

47. UNICEF Canada, Torvie AJ, Callegari LS, Schiff MA, Debiec KE, Sheppard AJ, et al. Birth outcomes among first nations, inuit and métis populations. Health Rep. 2017;28(11):11-6.

48. Smylie J, Crengle S, Freemantle J, Taualii M. Indigenous birth outcomes in Australia, Canada, New Zealand and the united STates - an overview. Open Womens Health J. 2010;4(2):7-17. https://doi.org/10.2174/1874291201004020007.

49. Smylie J, Fell D, Ohlsson A. System JWG on FNII and MIM of the CPS. A review of Aboriginal infant mortality rates in Canada: striking and persistent 
Aboriginal/non-Aboriginal inequities. Can J Public Health. 2010;101(2):143-8. https://doi.org/10.1007/BF03404361.

50. Tarrant M, Gregory D. Exploring childhood immunization uptake with first nations mothers in North-Western Ontario, Canada. Issues Innov Nurs Pract. 2003;41(1):63-72

51. The Chief Public Health Officer of Canada. Health Status of Canadians: Report of the Chief Public Health Officer. What Is Influencing Our Health? Ottawa; 2016. Available from: https://www.canada.ca/en/public-health/ corporate/publications/chief-public-health-officer-reports-state-public-healthcanada/2016-health-status-canadians.html. Accessed 13 Apr 2021.

52. Wilson L, Pakes B, Murphy M, Atkinson K, Bell C, Wilson K. Connecting remote populations to public health: the case for a digital immunisation information system in Nunavut. Int J Circumpolar Health. 2017;76(1): 1358566. https://doi.org/10.1080/22423982.2017.1358566.

53. Information $\mathrm{Cl}$ for $\mathrm{H}$. Children Vulnerable in Areas of Early Development: $\mathrm{A}$ Determinant of Child Health. Ottawa: $\mathrm{ClH} ; 2014$.

54. Foster EM, Jiang M, Gibson-Davis CM. The effect of WIC program on the health of newborns. Health Serv Res. 2010;45(4):1083-104. https://doi.org/1 0.1111/j.1475-6773.2010.01115.x.

55. Katz A, Kinew KA, Star L, Taylor C, Koseva I, Lavoie J, et al. The health status of and access to healthcare by registered first nation peoples in Manitoba; 2019. p. 224.

56. Statistics Canada. 2017. Canada [Country] and Canada [Country] (table). Census Profile. 2016 Census. Statistics Canada Catalogue no. 98-316X2016001. Ottawa. Released November 29, 2017. https://www12.statcan.gc. ca/census-recensement/2016/dp-pd/prof/index.cfm?Lang=E. Accessed 13 Apr 2021.

\section{Publisher's Note}

Springer Nature remains neutral with regard to jurisdictional claims in published maps and institutional affiliations.

Ready to submit your research? Choose BMC and benefit from:

- fast, convenient online submission

- thorough peer review by experienced researchers in your field

- rapid publication on acceptance

- support for research data, including large and complex data types

- gold Open Access which fosters wider collaboration and increased citations

- maximum visibility for your research: over $100 \mathrm{M}$ website views per year

At $\mathrm{BMC}$, research is always in progress.

Learn more biomedcentral.com/submissions 